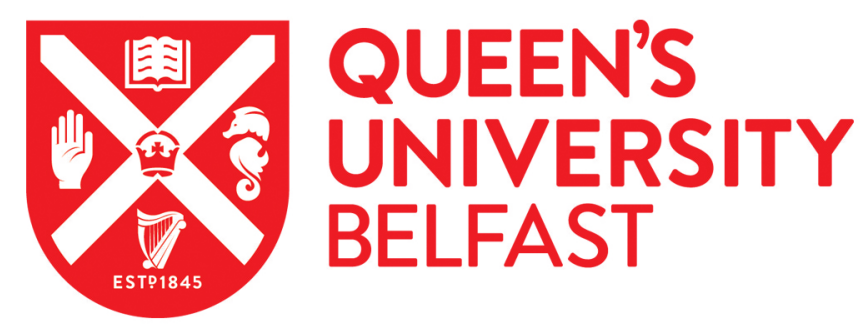

\title{
The effect of through-thickness compressive stress on mode II interlaminar crack propagation: A computational micromechanics approach
}

Varandas, L. F., Arteiro, A., Bessa, M. A., Melro, A. R., \& Catalanotti, G. (2017). The effect of through-thickness compressive stress on mode II interlaminar crack propagation: A computational micromechanics approach. Composite Structures, 182, 326-334. https://doi.org/10.1016/j.compstruct.2017.09.020

Published in:

Composite Structures

Document Version:

Peer reviewed version

Queen's University Belfast - Research Portal:

Link to publication record in Queen's University Belfast Research Portal

Publisher rights

(c) 2017 Elsevier Ltd. All rights reserved.

This manuscript version is made available under the CC-BY-NC-ND 4.0 license http://creativecommons.org/licenses/by-nc-nd/4.0/,which permits distribution and reproduction for noncommercial purposes, provided the author and source are cited.

\section{General rights}

Copyright for the publications made accessible via the Queen's University Belfast Research Portal is retained by the author(s) and / or other copyright owners and it is a condition of accessing these publications that users recognise and abide by the legal requirements associated with these rights.

\section{Take down policy}

The Research Portal is Queen's institutional repository that provides access to Queen's research output. Every effort has been made to ensure that content in the Research Portal does not infringe any person's rights, or applicable UK laws. If you discover content in the Research Portal that you believe breaches copyright or violates any law, please contact openaccess@qub.ac.uk. 


\section{Accepted Manuscript}

The effect of through-thickness compressive stress on mode II interlaminar crack propagation: a computational micromechanics approach

L. Varandas, A. Arteiro, M.A. Bessa, A.R. Melro, G. Catalanotti

PII: S0263-8223(17)31903-7

DOI: http://dx.doi.org/10.1016/j.compstruct.2017.09.020

Reference: COST 8883

To appear in:

Composite Structures

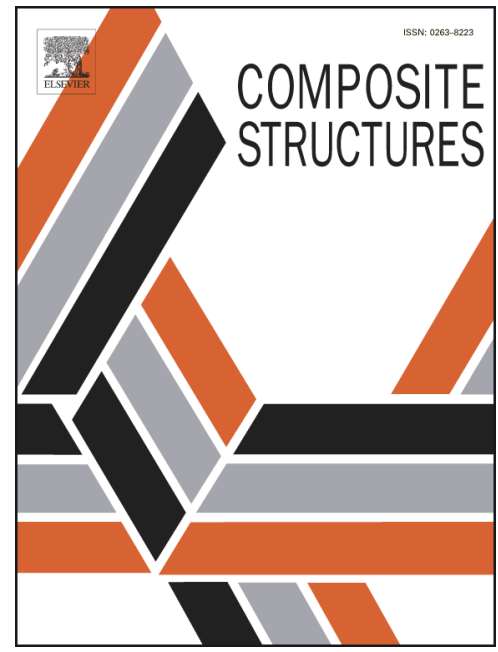

Received Date: $\quad$ 19 June 2017

Revised Date: $\quad 24$ August 2017

Accepted Date: $\quad 14$ September 2017

Please cite this article as: Varandas, L., Arteiro, A., Bessa, M.A., Melro, A.R., Catalanotti, G., The effect of throughthickness compressive stress on mode II interlaminar crack propagation: a computational micromechanics approach, Composite Structures (2017), doi: http://dx.doi.org/10.1016/j.compstruct.2017.09.020

This is a PDF file of an unedited manuscript that has been accepted for publication. As a service to our customers we are providing this early version of the manuscript. The manuscript will undergo copyediting, typesetting, and review of the resulting proof before it is published in its final form. Please note that during the production process errors may be discovered which could affect the content, and all legal disclaimers that apply to the journal pertain. 


\title{
The effect of through-thickness compressive stress on mode II interlaminar crack propagation: a computational micromechanics approach
}

\author{
L. Varandas ${ }^{\mathrm{a}}$, A. Arteiro ${ }^{\mathrm{b}}$, M.A. Bessa ${ }^{\mathrm{c}}$, A.R. Melro ${ }^{\mathrm{d}}$, G. Catalanotti ${ }^{\mathrm{e}}, *$ \\ ${ }^{a}$ INEGI, Rua Dr. Roberto Frias, 400, 4200-465 Porto, Portugal. \\ ${ }^{b}$ DEMec, Faculdade de Engenharia, Universidade do Porto, Rua Dr. Roberto Frias, 4200-465, Porto, Portugal \\ ${ }^{c}$ Graduate Aerospace Laboratories, California Institute of Technology, Pasadena, CA, United States \\ ${ }^{d}$ Advanced Composites Centre for Science and Innovation (ACCIS), Department of Aerospace Engineering, University \\ of Bristol, BS8 1TR, UK \\ e School of Mechanical and Aerospace Engineering, Queen's University Belfast, Belfast BT9 5AH, UK
}

\begin{abstract}
A micromechanics framework for modelling the mode II interlaminar crack onset and propagation in fibre-reinforced composites is presented with the aim of i) modelling the micro-scale failure mechanisms that underlie interlaminar crack propagation, and ii) determining the effect of the through-thickness pressure on mode II fracture toughness. An algorithm for the generation of the fibre distribution is proposed for the generation of three-dimensional Representative Volume Elements (RVEs). Appropriate constitutive models are used to model the different dissipative effects that occur at the crack propagation. Numerical predictions are compared with experiments obtained in previous investigations: it is concluded that the proposed micromechanical model is able to simulate conveniently the interlaminar crack propagation and to take into account the effect of the through-thickness pressure on mode II interlaminar fracture toughness.

Keywords: Delamination, Fracture toughness, Computational mechanics, Finite element analysis (FEA), through-thickness compressive stress
\end{abstract}

\section{Introduction}

At the micro-scale, interlaminar crack propagation is a complex mechanism that involves different dissipative phenomena: matrix cracking and plasticity, fibre-matrix debonding, crack branching and migration. At the macro-scale all this different mechanisms are ignored; a clear crack can be easily ${ }_{5}$ identified and the dissipated energies that oppose its propagation are lumped into a macroscopic parameter: the interlaminar fracture toughness.

\footnotetext{
* Corresponding author

Email address: G.Catalanotti@qub.ac.uk (G. Catalanotti)
} 
Fracture toughness is one of the key parameters on which rely both analytical and numerical strength analysis methods, and well known experimental techniques are used for its determination $[1$, 2, 3, 4, 5]. Test methods, however, allow the measurement of the interlaminar fracture toughness for mode I, II, and mixed mode, only under well-prescribed conditions. They cannot be used for general layups and require complex calibration and post-processing. Moreover, complex stress states cannot be easily applied and the study of the different failure mechanisms at the micro-scale is simply neglected.

Under these circumstances, micromechanics may be used to overcome these limitations: i) there are no limits to the layup that can be studied; ii) damage mechanisms associated with the interlaminar and investigated; iii) triaxial stress states can be easily applied and their effect on fracture properties easily assessed.

One case of particular interest of triaxial stress states is obtained imposing a compressive throughthickness stress. This is of great importance for mechanically fastened joints (bolted joints or filled hole parameters and in particular the mode II interlaminar fracture toughness. It should be remarked that the mode II interlaminar fracture toughness is of major importance when modelling delamination in bolted joints because the bolt, constraining the reciprocal movement of the plies, allows the crack to propagate only in pure mode II being the mode I completely restrained. If the effect that the throughmethods will yield conservative predictions that would result in an increase of both the cost and the weight of the joint.

It has been shown experimentally that the mode II interlaminar fracture toughness increases with the applied compressive stress [6, 7, [8, 9]. Cartié et al. 6] performed End Notched Flexural (ENF) tests in a pressurised environment up to $100 \mathrm{MPa}$. They observed that for the material system investigated, IM7/977-2 carbon-epoxy composite, an increase of $25 \%$ of the fracture toughness was obtained when the pressure increased from 0.4 to $90 \mathrm{MPa}$. Bing and Sun 7], implicitly assuming the equivalence between the intralaminar fracture toughness along the fibre direction and the interlaminar fracture toughness, reached the same conclusions using an off-axis compressive specimen. Li et al. [8] investigated numerically the influence of compressive stress on mode II damage evolution based on the cut-ply and dropped-ply experiments and developed, as well, an interfacial failure model with modified failure initiation and propagation criteria to take into account the effect of compression. They concluded that the increase of the mode II fracture toughness is the result of the increased shear strength due to the applied compressive stress. Finally, Catalanotti et al. [9] designed and performed experiments on Transverse Crack Tension (TCT) specimens loaded with through-thickness compressive stress and noted an increase in the fracture toughness that can be assumed to be linear as a first order 
approximation, as suggested by other researchers [7, 8]:

$$
\mathcal{G}_{I I}^{c}=\mathcal{G}_{I I 0}^{c}\left(1+\eta\left\langle-\sigma_{33}\right\rangle\right)
$$

where $\mathcal{G}_{I I 0}^{c}$ is the value of the mode II fracture toughness when no through-thickness pressure is applied, $\mathcal{G}_{I I}^{c}$ is the enhanced value of the mode II fracture toughness due to the through-thickness pressure $\sigma_{33}$, $\langle\cdot\rangle$ are the McAuley brackets, and $\eta$ is an empirical parameter that was found to be $\eta=0.0035 \mathrm{MPa}^{-1}$ for IM7 $7 / 8552$.

The mechanism that leads to an increase of the fracture toughness has not been completely understood and more efforts need to be made to fully understand this mechanism. Here, computational micromechanics is used to investigate the effect of the through-thickness stress on mode II interlaminar crack propagation. It will be shown that using appropriate constitutive models for the composite constituents and for the fibre-matrix interface it is possible to model the interlaminar crack propagation in mode II and to take into account the effect of the through-thickness compressive stress.

\section{Generation of the fibre distribution}

A modification of the algorithm presented in [10] is used for the generation of the fibre distribuof the Final RVE (the distribution obtained after the fibres have been placed randomly).

\subsection{Compact RVE}

The Compact RVE is formed by a periodic configuration of unit cells. These unit cells are formed by two circles with a radius $r$ and with centres given by the following expressions:

$$
\boldsymbol{v}_{0}=\left\{\begin{array}{l}
0 \\
r
\end{array}\right\}, \quad \boldsymbol{v}_{1}=\left\{\begin{array}{c}
r \\
r(\sqrt{3}+1)
\end{array}\right\}
$$

65

After one unit cell is created, the creation process is repeated the same amount of times in the thickness $(y y-)$ direction, $N$, and in the transverse $(x x-)$ direction, $M$ (Figure11). Therefore, the centre 
of the $i$-th fibre will have the following coordinates:

$$
\boldsymbol{v}_{i}^{m n}=\left\{\begin{array}{c}
v_{i x}^{m n} \\
v_{i y}^{m n}
\end{array}\right\}=\boldsymbol{v}_{i}+\left\{\begin{array}{c}
2 r(m-1) \\
2 \sqrt{3} r(n-1)
\end{array}\right\}
$$

where $m=1, \ldots, M, n=1, \ldots, N$ and:

$$
\begin{gathered}
M=\left\lfloor\frac{H}{4 r}+\frac{1}{2}\right\rfloor-1, \\
N=\left\lfloor\sqrt{\frac{N p_{\text {trial }} \sqrt{3}}{2}}\right\rfloor+3
\end{gathered}
$$

being $H$ the width of the RVE (Figure1), $N p_{\text {trial }}$ the number of fibres in the Compact RVE according to its area and fibre volume fraction input value, and the operator $\lfloor\cdot\rceil$ the round function.

[Figure 1 about here.]

The number of fibres inside the RVE is:

$$
N p=2 M N
$$

\subsection{Initial RVE}

Following [10], the coordinates of the fibres inside the Initial RVE read:

$$
\overline{\boldsymbol{v}}_{i}^{m n}=\left\{\begin{array}{c}
\bar{v}_{i x}^{m n} \\
\bar{v}_{i y}^{m n}
\end{array}\right\}=\left\{\begin{array}{c}
f_{x} v_{i x}^{m n} \\
f_{y} v_{i y}^{m n}
\end{array}\right\}
$$

where $f_{x}$ and $f_{y}$ are two correction factors defined as:

$$
f_{x}=\frac{H}{L_{x}}, \quad f_{y}=\frac{h-r}{L_{y}}
$$

where:

$$
L_{x}=2 r M, \quad L_{y}=2 r \sqrt{3} N
$$

It is important to notice that, depending on the number of repetitions of the unit cell, $M$ and $N$, the imposed fibre volume fraction, $\omega_{f}$, may differ from the actual one, $\omega_{f i}$. For this reason, the quality of the RVE generated is assessed using $\Delta$ and $\delta_{i j}$, that are defined as:

$$
\Delta=\frac{\left|\omega_{f i}-\omega_{f}\right|}{\omega_{f}}
$$




$$
\delta_{i j}=\sqrt{\left(\min \left\{\left|\bar{v}_{i}^{x}-\bar{v}_{j}^{x}\right|, H-\left|\bar{v}_{i}^{x}-\bar{v}_{j}^{x}\right|\right\}\right)^{2}+\left(\min \left\{\left|\bar{v}_{i}^{y}-\bar{v}_{j}^{y}\right|,(h-2 r)-\left|\bar{v}_{i}^{y}-\bar{v}_{j}^{y}\right|\right\}\right)^{2}}
$$

where $\bar{v}_{i}^{x}, \bar{v}_{i}^{y}, \bar{v}_{j}^{x}$ and $\bar{v}_{j}^{y}$ represent the $x$ and $y$ coordinates of the $i$-th and $j$-th fibre, respectively. The actual value of the fibre volume fraction, $\omega_{f i}$, reads:

$$
\omega_{f i}=N p \frac{A_{f}}{A}=N p \frac{r^{2} \pi}{H h}
$$

where $A_{f}$ and $A$ are the area of a single fibre and of the RVE respectively.

$\Delta$ evaluates if the real value of the fibre volume fraction deviates from the fibre volume fraction input value by computing the relative error. For the presented calculation, $\Delta \leqslant 0.1$ was used. $\delta_{i j}$ is the corrected Euclidean distance between fibres, whose value cannot be lower than the fibre diameter, $2 r$, otherwise the fibres interpenetrate. If any of the two conditions above mentioned is violated, then the algorithm decreases the value of $N$ of Eq. (5) by one, and the previous steps are repeated until the combination of $M$ by $N$ becomes possible. If $N$ reaches zero, then the input value of the fibre volume fraction is too high for the dimensions of the RVE that is being generated. In order to avoid this whilst not stopping the algorithm from running, it is necessary to lower the value of the fibre volume fraction until it reaches a possible one for the configuration of the RVE. However, if the fibre volume fraction reaches approximately zero, then $M$ is the variable that needs correction, i.e. the algorithm decreases the value of $M$ of Eq. (4) by one. $\omega_{f f}$ is equal to the input value of the fibre volume fraction, and, at this point, the fibre volume fraction $\omega_{f}$ is equal to its original input.

Obviously, the maximum theoretical value of the fibre volume fraction of a lamina depends strongly on its dimensions; Figure 2 shows the maximum fibre volume fraction as a function of the ratio $h / H$ for the cases of $H=30 r, H=50 r, H=75 r$ and $H=105 r$.

[Figure 2 about here.]

It is observed that the maximum fibre volume fraction changes with the width of the RVE. This is due to the fact that a higher value of the width of the RVE means a higher number of results retrieved, thus obtaining a more representative plot.

The algorithm for the generation of the RVEs is presented in Figure 3, emphasizing the generation of the Compact RVE and Initial RVE.

[Figure 3 about here.] 


\subsection{Final RVE}

The Final RVE is obtained by means of a stochastic process that moves the fibres randomly; to obtain a random distribution this process is repeated $K$ times. According to [10], the fibre distribution for a periodic RVE is completely random for a number of iterations greater than ten. However, since this RVE represents a lamina, i.e. with only periodic side boundaries, it is considered a completely random distribution of fibres with a number of iterations equal or greater than twenty $(K \geqslant 20)$. For every iteration, all the particles are randomly selected and moved according to a random displacement $\boldsymbol{u}$ that is defined by:

$$
\boldsymbol{u}=\left\{\begin{array}{l}
u_{x} \\
u_{y}
\end{array}\right\}=\left\{\begin{array}{c}
\rho \cos \theta \\
\rho \sin \theta
\end{array}\right\}
$$

where $\rho$ represents the radial coordinate and $\theta=2 \pi \mathcal{V}$ the azimuthal angle in terms of polar coordinates. $\mathcal{V}$ is a random scalar uniformly distributed on the open interval $(0,1)$.

For more detailed information regarding how the perturbation is applied to the Initial RVE, i.e., how the Final RVE is generated, the reader is referred to 10$]$.

In Figure 4 the Compact, Initial and the Final RVE $(K=20, r=4 \mu \mathrm{m}, H=120 \mu \mathrm{m}$ and $h=40 \mu \mathrm{m})$ for a fibre volume fraction input value of $55 \%$ are reported.

Since the Compact RVE represents one that has all the fibres arranged in a hexagonal packing, it is natural that its height is higher and its width is lower than the Initial RVE and, consequently, the Final RVE.

\section{Micromechanical model}

\subsection{Material constitutive models}

Appropriate constitutive models are used for the fibre, matrix and the fibre-matrix interface. Assuming that damage will be developed only in the matrix and at the fibre-matrix interface, a simple transversely isotropic, linear-elastic constitutive model is used to simulate the fibres. This is a reasonable assumption, being usually the interlaminar crack propagation dominated by the matrix and considering that bridging effects are negligible in mode II.

The constitutive law, based on the paraboloidal yield criterion proposed by Tschoegl [1]], and the damage model for the matrix are both based on work of Melro et al. [12]. For the sake of completeness, the highlights of the plasticity and damage model are reported in the following. 
The initial elastic behaviour is defined by a linear relation between the stress tensor, $\boldsymbol{\sigma}$, and the elastic strain tensor, $\varepsilon^{e}$ :

$$
\boldsymbol{\sigma}=\boldsymbol{D}^{e}: \varepsilon^{e}
$$

where $D^{e}$ is the elasticity fourth-order tensor. For an isotropic matrix and in terms of the deviatoric stress tensor, $\boldsymbol{S}$, and hydrostatic stress, $p=\frac{1}{3} \operatorname{tr}(\boldsymbol{\sigma})$, the elasticity law reads:

$$
\boldsymbol{S}=2 G_{m} \varepsilon_{d}^{e}, \quad p=K \varepsilon_{\nu}^{e}
$$

where $G_{m}$ is the shear modulus, $K$ is the bulk modulus, and $\varepsilon_{d}^{e}$ and $\varepsilon_{\nu}^{e}$, are, respectively, the elastic deviatoric strain tensor and elastic volumetric strain.

The paraboloidal yield criterion proposed by [11] can be defined as:

$$
f\left(\boldsymbol{\sigma}, \sigma_{Y_{c}}, \sigma_{Y_{t}}\right)=6 J_{2}+2\left(\sigma_{Y_{c}}-\sigma_{Y_{t}}\right) I_{1}-2 \sigma_{Y_{c}} \sigma_{Y_{t}}
$$

where $\sigma_{Y_{c}}$ and $\sigma_{Y_{t}}$ are the absolute values of the compressive and tensile yield strengths, $I_{1}=\operatorname{tr}\left(\boldsymbol{\sigma}_{i j}\right)$ is the first stress invariant and $J_{2}=\frac{1}{2} s_{i j} s_{i j}$ is the second invariant of the deviatoric stress tensor $\boldsymbol{s}_{i j}$.

A non-associative flow rule [12] was used to prevent positive volumetric plastic strain under hydrostatic pressure:

$$
\mathrm{g}=\sigma_{v m}^{2}+\alpha p^{2}
$$

where $\sigma_{v m}=\sqrt{3 J_{2}}$ is the Von Mises equivalent stress, $p=\frac{1}{3} I_{1}$ is the hydrostatic pressure and $\alpha$ is a material parameter responsible for the correct definition of the volumetric component of the plastic flow and it is given by the following equation:

$$
\alpha=\frac{9}{2} \frac{1-2 \nu_{p}}{1+\nu_{p}}
$$

with $\nu_{p}$ being the plastic Poisson's ratio. It is possible to write the increment in plastic deformation via the flow rule that used the plastic potential given in Eq. (17):

$$
\Delta \varepsilon^{p}=\Delta \lambda \frac{\partial \mathrm{g}}{\partial \sigma}
$$

with $\Delta \lambda$ being the plastic multiplier, subjected to the Kuhn-Tucker consistency conditions and to be updated via the return mapping algorithm [13]. 
Since only tension and compression yield strengths are being explicitly used to define the yield surface, hardening will be considered to affect both of these yield strengths. Hardening is considered dependent of the equivalent plastic strain:

$$
\sigma_{Y_{c}}=\sigma_{Y_{c}}\left(\varepsilon_{e}^{p}\right), \quad \sigma_{Y_{t}}=\sigma_{Y_{t}}\left(\varepsilon_{e}^{p}\right)
$$

The equivalent plastic strain $\varepsilon_{e}^{p}$ is defined as:

$$
\varepsilon_{e}^{p}=\sqrt{\frac{1}{1+2 \nu_{p}^{2}} \varepsilon^{p}: \varepsilon^{p}}
$$

The damage model only uses one damage variable, $d_{m}$, that affects the stiffness of the material once activated. Following [12], the following definition for the complementary free energy density of the material is proposed:

$$
\begin{aligned}
\mathscr{G}_{m}= & \frac{\sigma_{11}^{2}+\sigma_{22}^{2}+\sigma_{33}^{2}}{2 E_{m}\left(1-d_{m}\right)}-\frac{\nu_{m}}{E_{m}}\left(\sigma_{11} \sigma_{22}+\sigma_{22} \sigma_{33}+\sigma_{33} \sigma_{11}\right)+ \\
& +\frac{1+\nu_{m}}{E_{m}\left(1-d_{m}\right)}\left(\sigma_{12}^{2}+\sigma_{13}^{2}+\sigma_{23}^{2}\right)+\mathscr{G}_{m}^{p}
\end{aligned}
$$

where, $E_{m}, \nu_{m}$ and $d_{m}$ are the Young's modulus, the Poisson's ratio and the damage variable for the matrix, respectively. According to [14], this function must be a scalar one, positive definite and it must be zero at the origin with respect to the stresses. The quantity $\mathscr{G}_{m}^{p}$ represents the contribution of plastic flow to the stored energy.

To ensure that the damage process is irreversible, it is necessary to guarantee that the rate of change of the complementary free energy density is greater than the externally applied stress:

$$
\dot{\mathscr{G}}_{m}-\dot{\sigma}: \varepsilon \geqslant 0
$$

which can be written as:

$$
\left(\frac{\partial \mathscr{G}_{m}}{\partial \boldsymbol{\sigma}}-\boldsymbol{\varepsilon}\right): \dot{\boldsymbol{\sigma}}+\frac{\partial \mathscr{G}_{m}}{\partial d_{m}} \cdot \dot{d}_{m} \geqslant 0
$$

Finally, to ensure a positive dissipation of mechanical energy it is necessary for the strain tensor to be equal to the derivative of the complementary free energy density with respect to the stress tensor:

$$
\boldsymbol{\varepsilon}=\frac{\partial \mathscr{G}_{m}}{\partial \boldsymbol{\sigma}}=\frac{\boldsymbol{\sigma}}{2 G_{m}\left(1-d_{m}\right)}-\frac{\nu_{m} d_{m}}{E_{m}\left(1-d_{m}\right)} \boldsymbol{I} \cdot \boldsymbol{I}: \boldsymbol{\sigma}-\frac{\nu_{m}}{E_{m}} I_{1} \boldsymbol{I}
$$

Damage onset is defined by the following damage activation function:

$$
F_{m}^{d}=\phi_{m}^{d}-r_{m}
$$


where $\phi_{m}^{d}$ represents the loading function and $r_{m}$ is an internal variable related with the damage variable. More details of the model are reported in [12].

The damage variable defined for the matrix is given by:

$$
d_{m}=1-\frac{e^{A_{m}\left(3-\sqrt{7+2 r_{m}^{2}}\right)}}{\sqrt{7+2 r_{m}^{2}}-2}
$$

Fibre-matrix interface is modelled using the cohesive surfaces of the FE commercial software Abaqus ${ }^{\circledR}$. The initiation of the softening process is predicted using a stress-based quadratic failure criterion [15]:

$$
\left(\frac{\left\langle\tau_{3}\right\rangle}{\tau_{3}^{0}}\right)^{2}+\left(\frac{\tau_{2}}{\tau_{2}^{0}}\right)^{2}+\left(\frac{\tau_{1}}{\tau_{1}^{0}}\right)^{2}=1
$$
fracture toughness [18].

$$
d_{i}=\int_{\delta_{m}^{0}}^{\delta_{m}^{f}} \frac{T_{i}}{\mathcal{G}_{i}^{c}-\mathcal{G}_{i}^{0}} \mathrm{~d} \delta_{i}
$$

where $T_{i}$ and $\delta_{i}$ are the effective traction and separation, respectively, $\delta_{m}^{0}$ and $\delta_{m}^{f}$ are the effective separation at damage initiation and complete failure, respectively, $\mathcal{G}_{i}^{0}$ is the elastic energy release rate at damage initiation and $\mathcal{G}_{i}^{c}$ the interfacial (between fibre and matrix) fracture toughness, that is evaluated according to the Benzeggagh-Kenane interaction law [17].

\subsection{Details of the FE model: geometry, boundary conditions and material properties}

The RVE generated has the same geometry and boundary conditions of a TCT specimen, but at the micro-scale. The TCT specimen, whose geometrical parameters are represented in Figure [5 was introduced by Prinz and Gädke, and it is used as a test method to measure the mode II interlaminar

[Figure 5 about here.]

The test consists of an unidirectional laminate, loaded in tension, that contains a transverse cut from which, increasing the load, four interlaminar cracks will develop and propagate in pure mode II.

When the remote stress reaches its peak value, $\sigma_{p}$, the four cracks will propagate unstably, and the critical value of the energy release rate is obtained as:

$$
\mathcal{G}_{I I}^{c}=\sigma_{p}^{2} \frac{W}{2 E_{1}}\left(\frac{1}{\xi}-1\right)
$$


where $E_{1}$ is the laminate Young's modulus in the longitudinal $(z z-)$ direction, and $\xi$ is the cut factor, $\xi=\hat{W} / W$, defined as the ratio between the thickness of the uncut plies, $2 \hat{W}$, and the thickness of the specimen, $2 W[19]$. A cut factor of $\xi=0.5$ was used for the RVE.

Eq. (30) is derived with the assumption that the delamination crack length is sufficiently large for a cracked region with uniform stress distribution to exist. In that case, the energy release rate can be computed from the difference of elastic energy in the cracked and uncracked regions. The solution is independent of the crack length and of the orthotropy of the material [20].

Using the algorithm previously described for the generation of the distribution of fibres, a 2D RVE is generated simulating two plies bonded together (Figure 6a). The 3D RVE is obtained by extruding the 2D RVE in the longitudinal ( $z z-)$ direction, as reported in Figure 6b Only one half of the TCT is modelled in order to reduce the computational effort. A certain distance is given between plies in order to appropriately evaluate the interlaminar damage, creating a thicker resin rich area with a thickness of $7 \mu \mathrm{m}$. The presence of this resin-rich area has been found experimentally and reported by several authors [21, 22, 23]. Finally, the transverse cut, $\hat{w}$ long, is created on the bottom (Figure 6b). The model has a width of $H=30 r=105 \mu \mathrm{m}$ and each ply of the RVE has a height of $h=10 \mathrm{r}=35 \mu \mathrm{m}$, being the total thickness of the model (including the resin-rich area), $W$, equal to $84 \mu \mathrm{m}$.

[Figure 6 about here.]

It needs to be noted that the thickness of the RVE should not influence the interlaminar crack propagation for sufficiently thick RVEs. Our preliminary simulations, presented in Figure 7, showed that the thickness of the RVE was observed to have a negligible influence on the peak load of the stress-displacement curve for $h \geqslant 10 r$. Therefore the thickness was fixed at $h=10 r$ henceforth.

[Figure 7 about here.]

Figure 8 represents the boundary conditions applied to the model.

[Figure 8 about here.]

Both fibre and matrix are modelled by means of a C3D4, three-dimensional tetrahedral continuum solid elements with an average size of $1.7 \mu \mathrm{m}$.

Table 1 shows the geometrical and material properties of standard carbon fibres used in a single ply of the 2D RVE, while Table 2 reports the material properties used for the matrix.

[Table 2 about here.] 
The material properties of the fibre-matrix interface are presented in Table 3. These parameters are based on experimental data [24] and also on previous micromechanical simulations [25, 26].

[Table 3 about here.]

equ

\section{Numerical predictions and discussion}

\subsection{Effect of the size of the RVE}

Preliminary studies are conducted to assess the influence of the size of the RVE. To allow a complete development of the fracture process zone, and therefore obtaining a representative value of the mode II interlaminar fracture toughness (from the peak in the load-displacement curve), different lengths of the RVE are analysed. The lengths tested were 4, 7, 10, 12.5, 15 and 20 times the width $(H)$ of the RVE and numerical predictions of the stress-strain (engineering strain) curves are reported in Figure 9 and in Table 4

[Figure 9 about here.]

[Table 4 about here.]

It is observed that the peak load depends on the size of the RVE only when its length is lower than $10 H$, whereas it is assumed to be constant when the length is larger or equal to $10 H$. It can be concluded that if the length of the RVE is $10 H$ (or larger) the model will yield results that are geometry independent. Therefore, a length of $2 L=10 H=1.05 \mathrm{~mm}$ is chosen in order to guarantee both geometry independence of the results and to minimize the computational effort. It should be noted that the computational effort is still considerable with these dimensions. The micromechanical model still contains approximately thirteen million elements.

\subsection{Simulation of interlaminar crack propagation}

After determining the minimum size of the RVE, numerical simulations are performed to model the onset and propagation of the crack in mode II. Figure 10 shows the matrix contour plots of the equivalent plastic strain and of the damage variable in the cracked region at onset of crack propagation.

[Figure 10 about here.]

Numerical predictions are presented in Figure 11 where the load-displacement curve is reported. In the curve, different points are indicated and associated with the corresponding contour plot of the damage variable, $d_{m}$.

[Figure 11 about here.] 
The following points are identified in the curve of Figure 11] A) onset of crack propagation, which occurs at an applied displacement of $1.05 \mu \mathrm{m}$; B) substantial crack propagation in the resin-rich region, but fracture process zone not completely developed; C) fracture process zone is completely developed at the maximum remote stress; D) unstable crack propagation. Video 1 shows the different stages of the crack onset and propagation obtained numerically. The state variable plotted corresponds to the damage variable $d_{m}$.

[Video 1 about here.]

\subsection{Effect of through-thickness pressure}

The same RVE was used to study the effect of the through-thickness compressive stress on mode II interlaminar fracture toughness. These simulations were performed in two steps: in the first, the through-thickness compressive stress $\left(\sigma_{33}\right)$ was applied to the upper surface of the model to generate the pressure loading conditions depicted in Figure 12 in the second, the velocity type boundary condition in the longitudinal $(z z-)$ direction $\left(\dot{u}_{z}\right)$ is applied while keeping constant the value of the compressive pressure.

Simulations were conducted for increments of $20 \mathrm{MPa}$ of the through-thickness pressure in the range $0 \mathrm{MPa} \leqslant-\sigma_{33} \leqslant 80 \mathrm{MPa}$. Figure 13, shows the load-displacement curves obtained for different through-thickness pressures applied.

[Figure 13 about here.]

It is observed that the peak load, and consequently, the associated value of the mode II interlaminar fracture toughness increases with the through-thickness compressive pressure applied. Therefore, it is concluded that the micromechanical model can capture the pressure-dependent nature of the fracture properties. Since the elements are deleted throughout the simulations (to avoid numerical error due to excessive distorted elements), the model is not able to replicate the rise of the remote stress due to 275 the frietion between the fracture surfaces that occurs after crack propagation has become unstable [9].

The fracture toughness values are calculated using Eq. (30) by substituting the stress by the peak of the different stress-displacement curves, being $E_{1}$ the laminate Young's modulus simply calculated using the rule of mixtures:

$$
E_{1}=\omega E_{1 f}+(1-\omega) E_{m}
$$


where the fibre volume fraction of the whole model reads:

$$
\omega=2 N p \frac{\pi r^{2}}{H W}
$$
especially for the resins used in prepregs. In this case, in fact, manufacturers do not usually make commercially available their resins and a complete characterization of these is missing. Therefore, those fundamental micromechanical parameters are taken from the literature, estimated from other parameters, or simply guessed from other resins. Clearly, this represents a serious source of disagreement

Table 5 presents the values of the peak stresses and the mode II interlaminar fracture toughness calculated using Eq. (30) for the different numerical predicted stress-displacement curves with different applied through-thickness compressive stresses.

[Table 5 about here.]

Using Eq. (11), the linear regression curve was calculated for the numerical predictions of the mode II interlaminar fracture toughness values (Figure 14) and a value of $\eta=0.0131 \mathrm{MPa}^{-1}$ was found.

[Figure 14 about here.]

It should be pointed out that the values of the fracture toughness reported in Table 5 are at least one order of magnitude lower than those obtained experimentally 9]. The reason for this is that, despite its apparent simplicity at macro-scale, the interlaminar crack propagation is, at the micro-scale, a very complex phenomenon and several simplifications were assumed when setting up the proposed micromechanical model.

First of all, in the case of unidirectional composites, the interlaminar region of the fibre distribution may differ substantially from the distribution obtained numerically. This is because after curing the plies, they are not two separate entities identified by perfect boundaries, and therefore fibres of different plies may interlace and interpenetrate the adjacent ply, giving rise to fibre-bridging mechanisms that increase the propagation value of the fracture toughness. If this is the case, a different algorithm for the generation of the fibre distribution needs to be proposed and damage of the fibres should be included.

Secondly, it should be mentioned that the micromechanical model requires the definition of micromechanical parameters necessary to describe the plasticity and failure of the matrix and the debonding at the fibre-matrix interface. Those micromechanical parameters are not always available and with the real scenario.

However, it should be noticed that the constitutive model used for the resin is able to represent the increase of the fracture toughness as described in Eq. (11) and reported in Figure 14. The value of $\eta$ is found to be equal to $\eta=0.0131 \mathrm{MPa}^{-1}$, different from $\eta=0.0035 \mathrm{MPa}^{-1}$ found for IM7 $/ 8552$ [9] . 
Together with the aforementioned reasons previously explained, it should be mentioned that during the simulations, damaged elements $\left(d_{m}=0.9999\right)$ have been removed. This numerical artifice was required to avoid numerical errors due to the excessive distortion of the elements. Element deletion does not allow the recovery of the load due to friction after the crack has propagated [9]. It should be observed, however, that the increase of the fracture toughness due to the through-thickness stress is captured, at least partially, by the constitutive model of the resin. Therefore, the increase of the fracture toughness is not only due to the friction between the crack faces, but it can also be explained by triaxiality effects, which the appropriate constitutive model is able to address.

\section{Conclusions}

The main findings of this work can be summarised in the following concluding remarks.

i) An algorithm for the generation of the fibre distribution has been proposed for the micromechanical modelling of interlaminar crack propagation. The algorithm was developed on the basis of the work presented in [10] and it allows the generation of fibre distributions that are representative of an entire ply. To achieve these results, the thickness conditions of periodicity have been removed and only that on the transverse direction has been maintained.

ii) Additional improvements of the numerical predictions are possible: a) a better representation of the microstructure needs to be proposed, to model effectively the possible interlacing between fibres of different plies; b) damage of the fibre needs to be considered in this case to model bridging phenomena; c) the microstructural material parameters of the matrix and of the fibre-matrix interface need to be extensively characterized.

iii) The use of the appropriate constitutive model for the matrix and for the fibre-matrix interface allows a correct simulation of the interlaminar crack propagation and it takes into account the effect of the through-thickness compressive pressure. The mode II interlaminar fracture toughness is shown to increase linearly with the applied compressive stress, which is in qualitative agreement with previous experimental results [9]. Therefore, it can be concluded that the increase of the fracture toughness is not only due to the friction that may exist between the crack surfaces, but also due to the stress triaxiality at the crack tip.

iv) The modelling strategy used here will be used in the future to model, after appropriate modifications, other damage mechanisms associated with the interlaminar crack propagation such as fibre bridging and/or crack migration. 


\section{Acknowledgements}

The first author would like to thank the funding of Project NORTE-01-0145-FEDER-000022 SciTech - Science and Technology for Competitive and Sustainable Industries, cofinanced by Programa Operacional Regional do Norte (NORTE2020), through Fundo Europeu de Desenvolvimento

Regional (FEDER). The second author would like to thank the financial support provided by FCT - Fundação para a Ciência e a Tecnologia through National Funds in the scope of project MITP$\mathrm{TB} / \mathrm{PFM} / 0005 / 2013$.

\section{References}

[1] ASTM D5528-13, Standard Test Method for Mode I Interlaminar Fracture Toughness of Unidirectional Fiber-Reinforced Polymer Matrix Composites, 2013.

[2] ASTM D7905 / D7905M-14, Standard Test Method for Determination of the Mode II Interlaminar Fracture Toughness of Unidirectional Fiber-Reinforced Polymer Matrix Composites, 2014.

[3] ISO 15114:2014. Fibre-reinforced plastic composites - Determination of the mode II fracture resistance for unidirectionally reinforced materials using the calibrated end-loaded split (C-ELS) test and an effective crack length approach. Standard, International Organization for Standardization, Geneva, CH, 2014.

[4] T. Scalici, G. Pitarresi, G. Catalanotti, F.P. van der Meer, and A. Valenza. The Transverse Crack Tension test revisited: An experimental and numerical study. Composite Structures, 158:144 $159,2016$.

[5] ASTM D6671 / D6671M-13e1, Standard Test Method for Mixed Mode I-Mode II Interlaminar Fracture Toughness of Unidirectional Fiber Reinforced Polymer Matrix Composites, 2013.

[6] D. Cartié, P. Davies, M. Peleau, and I.K. Partridge. The influence of hydrostatic pressure on the interlaminar fracture toughness of carbon/epoxy composites. Composites Part B: Engineering, $37: 292-300,2006$.

[7] Q. Bing and C. T. Sun. Effect of compressive transverse normal stress on mode II fracture toughness in polymeric composites. International Journal of Fracture, 145(2):89-97, 2007.

[8] Xiangqian Li, Stephen R. Hallett, and Michael R. Wisnom. Predicting the effect of throughthickness compressive stress on delamination using interface elements. Composites Part A: Applied Science and Manufacturing, 39(2):218-230, 2008.

[9] G Catalanotti, C Furtado, T Scalici, G Pitarresi, F P Van Der Meer, and P.P. Camanho. The effect of through-the-thickness compressive stress on the mode II interlaminar fracture toughness. Submitted to Composite Structures, 2017. 
[10] G. Catalanotti. On the generation of RVE-based models of composites reinforced with long fibres or spherical particles. Composite Structures, 138:84-95, 2016.

[11] N. W. Tschoegl. Failure surfaces in principal stress space. Journal of polymer science Part C: Polymer symposia, 32(1):239-267, 1971.

[12] A. R. Melro, P. P. Camanho, F. M. Andrade Pires, and S. T. Pinho. Micromechanical analysis of polymer composites reinforced by unidirectional fibres: Part I-Constitutive modelling. International Journal of Solids and Structures, 50(11-12):1897-1905, 2013.

[13] E. A. de Souza Neto, D. Peric, and D. R. J. Owen. Computational Methods for Plasticity, volume 55. 2008.

[14] L.E. Malvern. Introduction to the Mechanics of a Continuos Medium. Engineering of the Physical Sciences, 33(1):238, 1969.

[15] Lin Ye. Role of matrix resin in delamination onset and growth in composite laminates. Composites Science and Technology, 33(4):257-277, 1988.

[16] Dassault Systèmes, Providence, RI, USA. ABAQUS Documentation.

[17] M. L. Benzeggagh and M. Kenane. Measurement of mixed-mode delamination fracture toughness of unidirectional glass/epoxy composites with mixed-mode bending apparatus. Composites Science and Technology, 56(4):439-449, 1996.

[18] Gadke M. Prinz R. Characterization of interlaminar mode I and mode II fracture in CFRP laminates. In Proceedings of international conference on spacecraft structures and mechanical testing, pages 97-102, 1991.

[19] A. Fink, P. P. Camanho, J. M. Andres, E. Pfeiffer, and A. Obst. Hybrid CFRP/titanium bolted joints: Performance assessment and application to a spacecraft payload adaptor. Composites Science and Technology, 70(2):305-317, 2010.

[20] T. Scalici, G. Pitarresi, G. Catalanotti, F. P. van der Meer, and A. Valenza. The Transverse Crack Tension test revisited: An experimental and numerical study. Composite Structures, 158(September):144-159, 2016.

[21] F. París, A. Blázquez, L. N. McCartney, and A. Barroso. Characterization and evolution of matrix and interface related damage in $[0 / 90]_{\mathrm{s}}$ laminates under tension. Part II: Experimental evidence. Composites Science and Technology, 70(7):1176-1183, 2010.

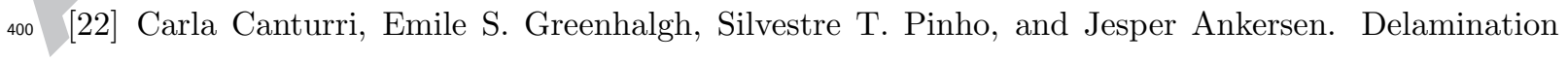
growth directionality and the subsequent migration processes - The key to damage tolerant design. Composites Part A: Applied Science and Manufacturing, 54:79-87, 2013.

[23] G. Borstnar, F. Gillard, M. N. Mavrogordato, I. Sinclair, and S. M. Spearing. Three-dimensional deformation mapping of Mode I interlaminar crack extension in particle-toughened interlayers. Acta Materialia, 103:63-70, 2016. 
[24] J. Varna, L. A. Berglund, and M. L. Ericson. Transverse single-fibre test for interfacial debonding in composites: 2. Modelling. Composites Part A: Applied Science and Manufacturing, 28(4):317326, 1997.

[25] A. Arteiro, G. Catalanotti, A. R. Melro, P. Linde, and P. P. Camanho. Micro-mechanical analysis of the in situ effect in polymer composite laminates. Composite Structures, 116(1):827-840, 2014.

[26] A. R. Melro, P. P. Camanho, F. M. Andrade Pires, and S. T. Pinho. Micromechanical analysis of polymer composites reinforced by unidirectional fibres: Part II-Micromechanical analyses. International Journal of Solids and Structures, 50(11-12):1906-1915, 2013. 


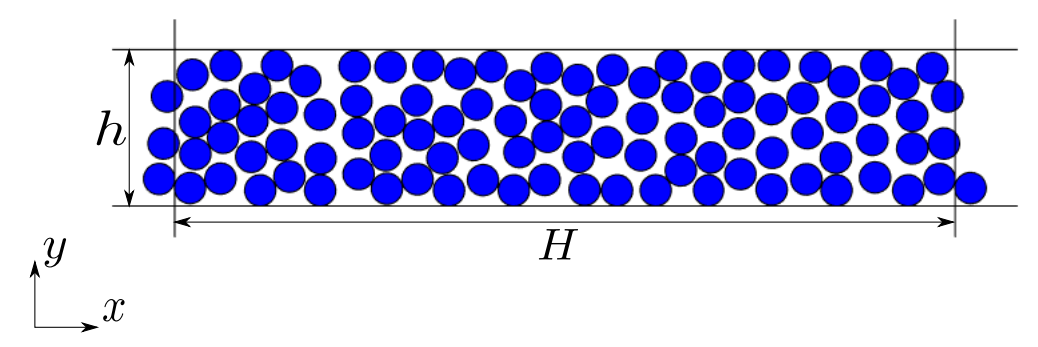

Figure 1: Dimensions of the RVE and coordinate system

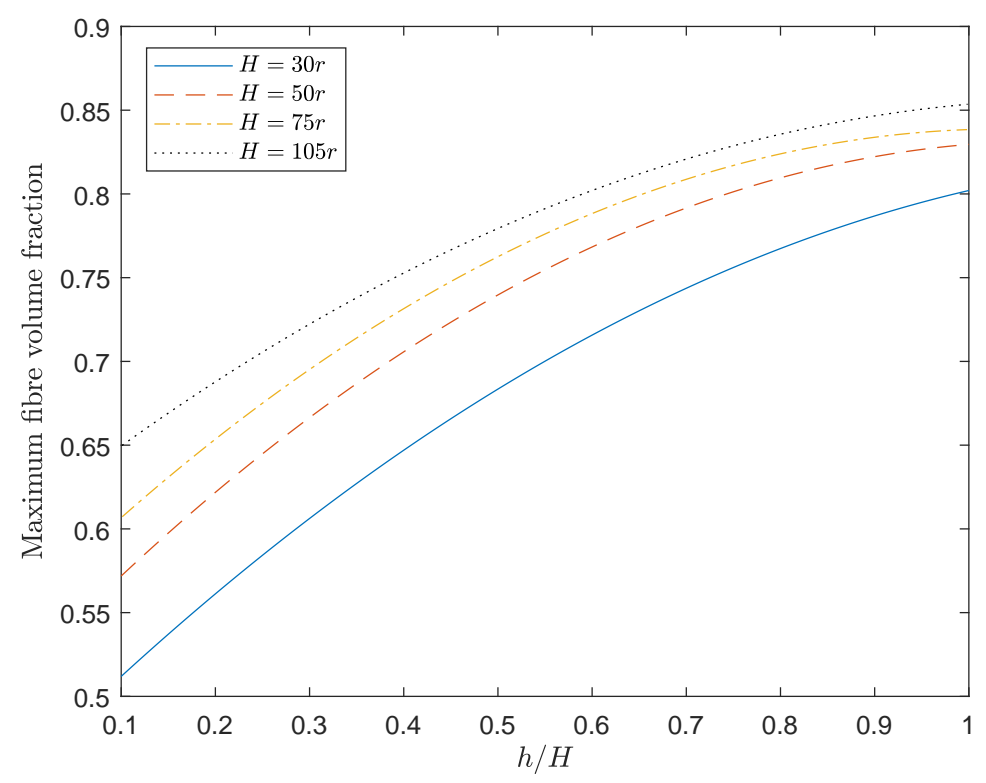

Figure 2: Dimensions of the RVE versus maximum fibre volume fraction 


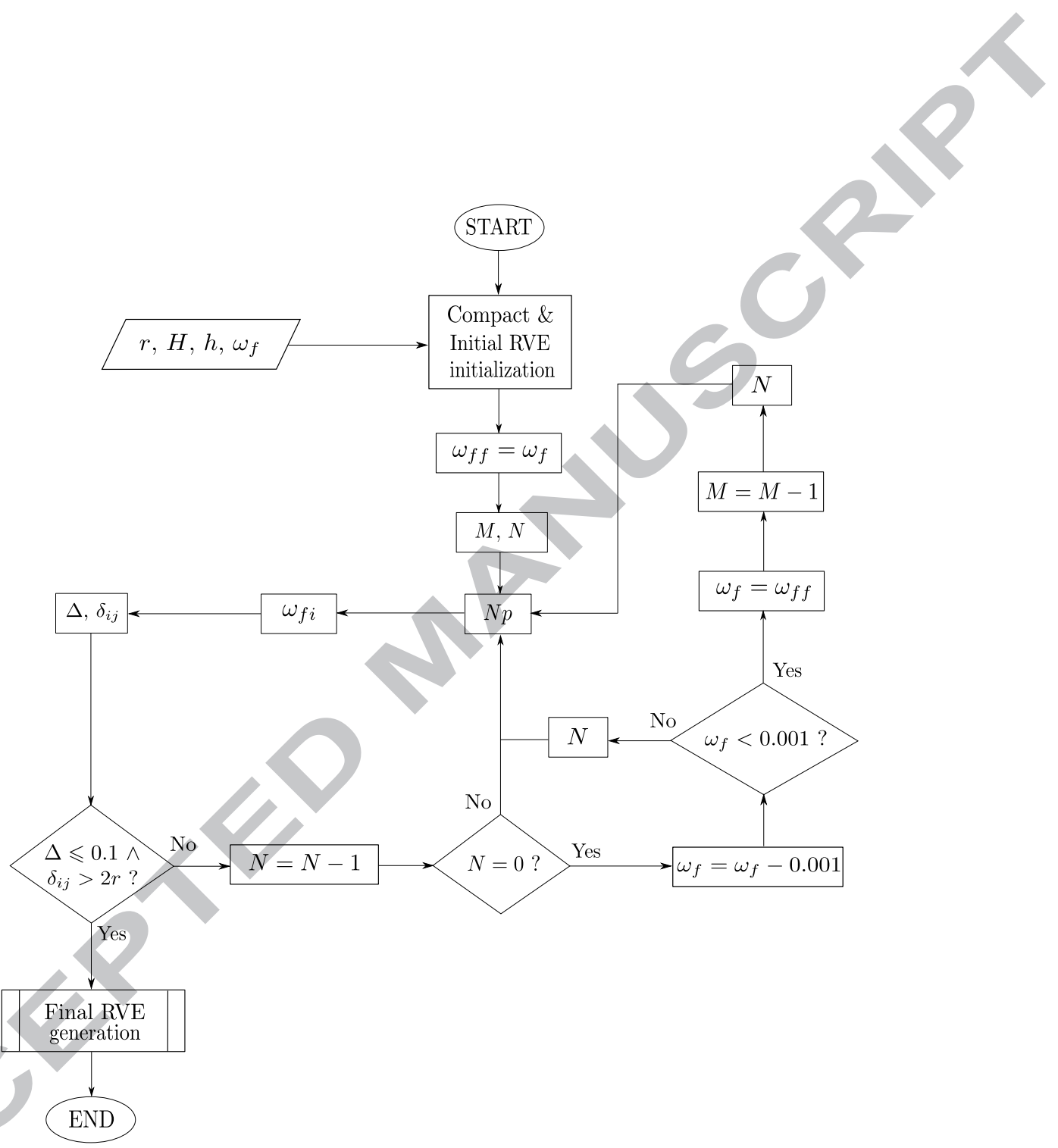

Figure 3: Explanation of the generation of the RVEs 


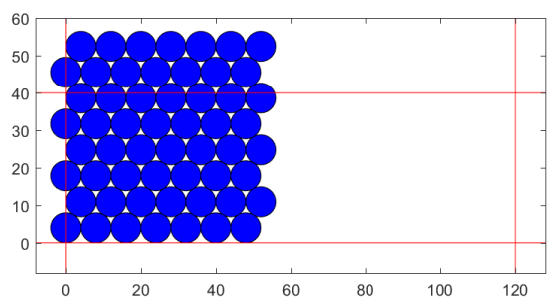

(a) Compact RVE

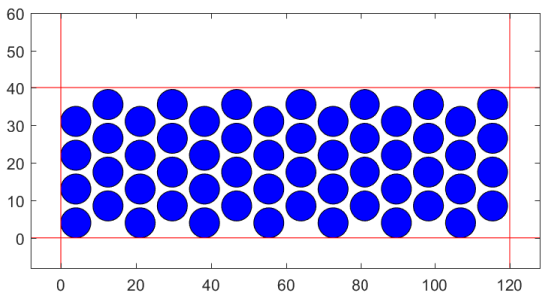

(b) Initial RVE

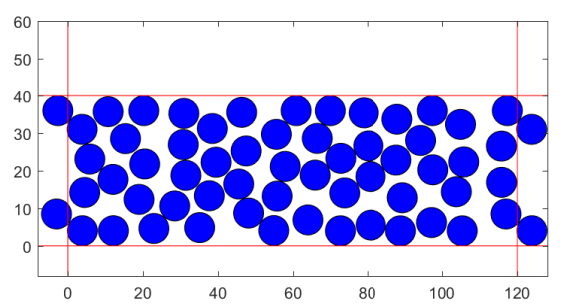

(c) Final RVE

Figure 4: RVEs with $\omega_{f}=55 \%$. The red lines indicate the boundaries imposed

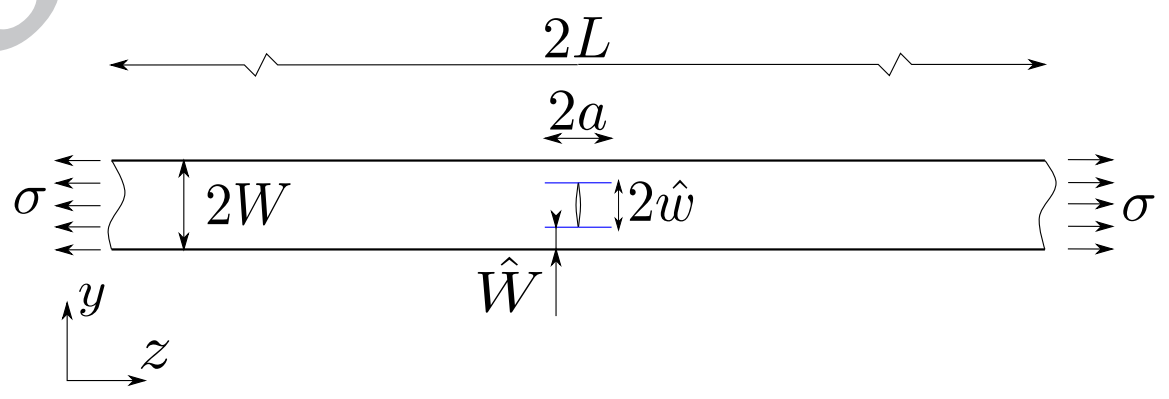

Figure 5: TCT specimen: geometrical parameters and coordinate system 


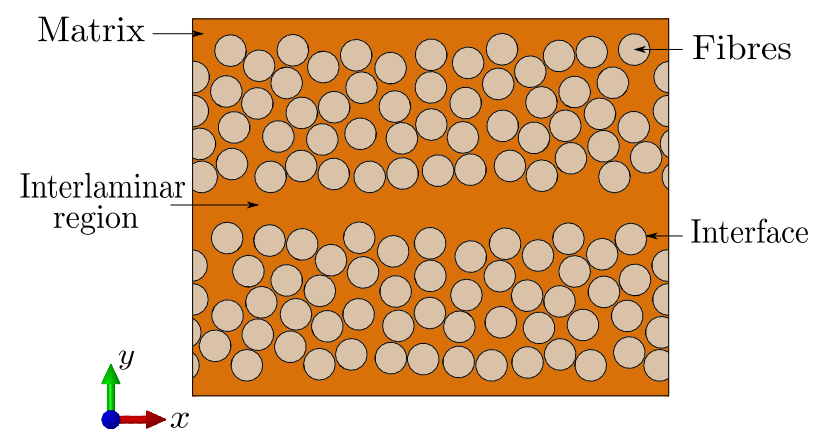

(a) 2D RVE

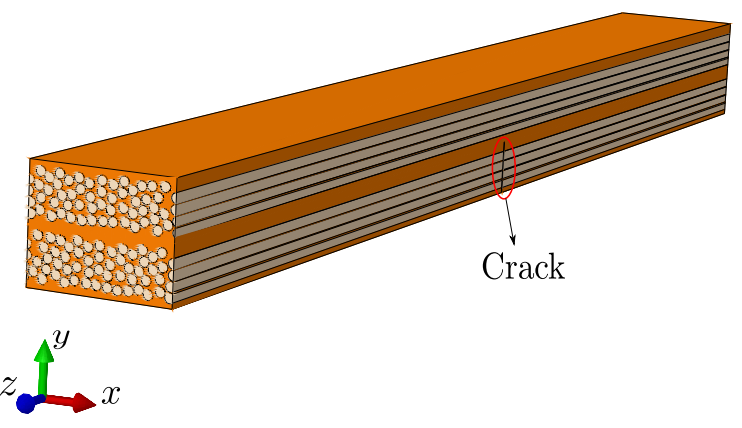

(b) 3D RVE

Figure 6: Different views of the TCT model

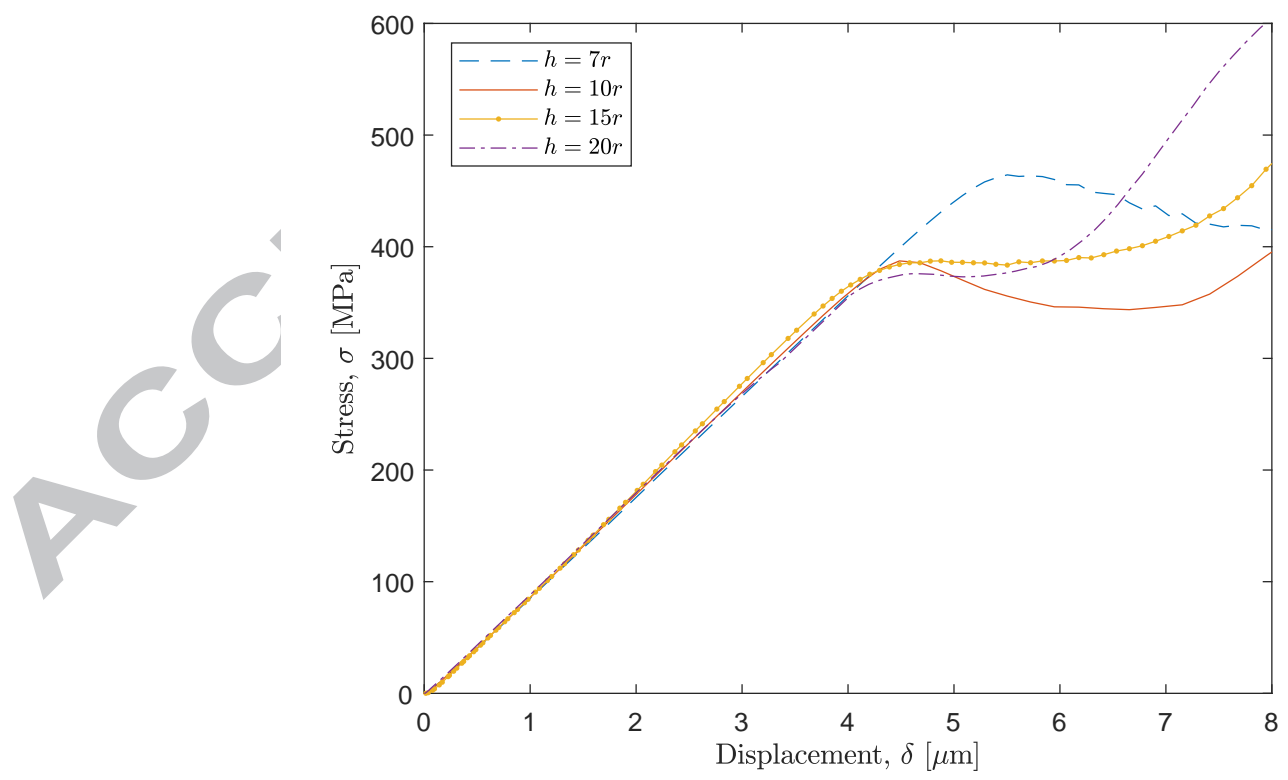

Figure 7: Numerical prediction of the stress-displacement curves obtained for different heights of the micromechanical TCT model $(H=30 r=105 \mu \mathrm{m}$ and $2 L=10 H=1.05 \mathrm{~mm})$ 


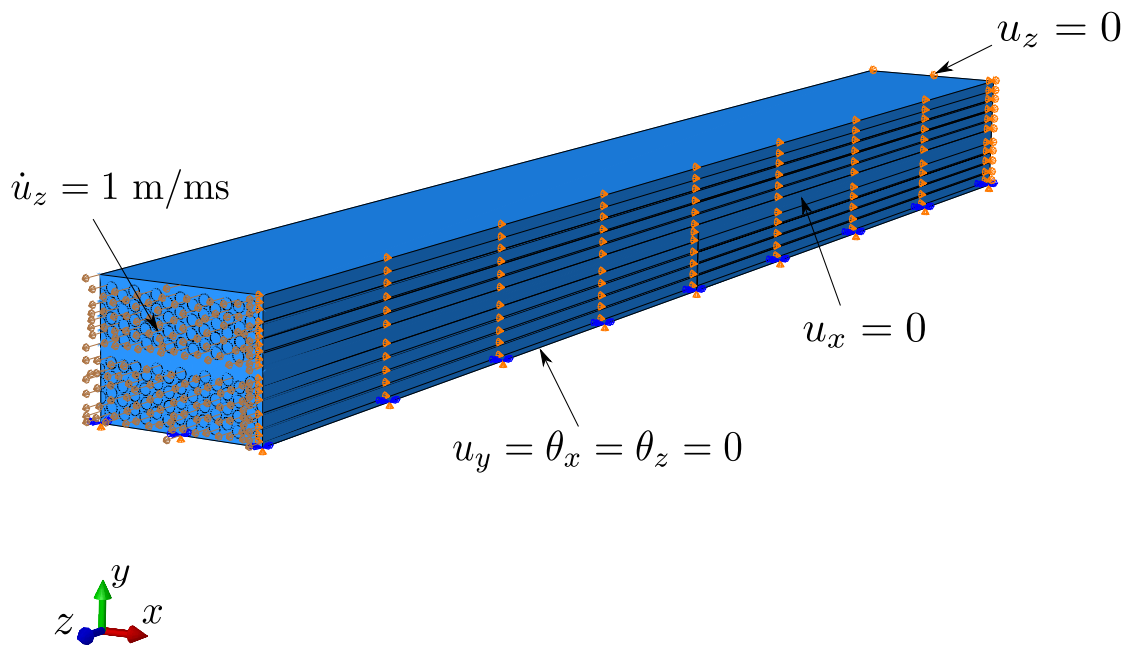

Figure 8: Boundary conditions applied to the model

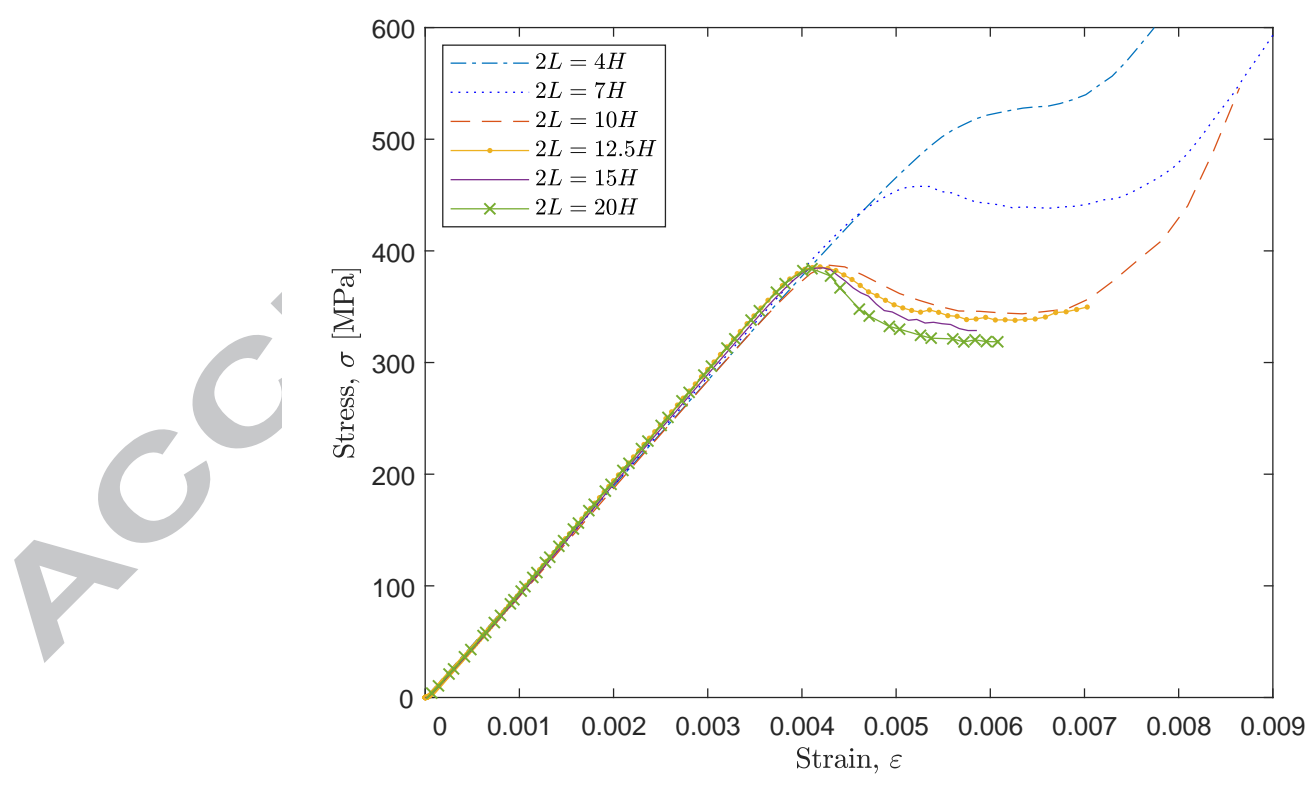

Figure 9: Numerical prediction of the stress-strain curves obtained for different lengths of the micromechanical TCT model $(H=30 r=105 \mu \mathrm{m})$ 

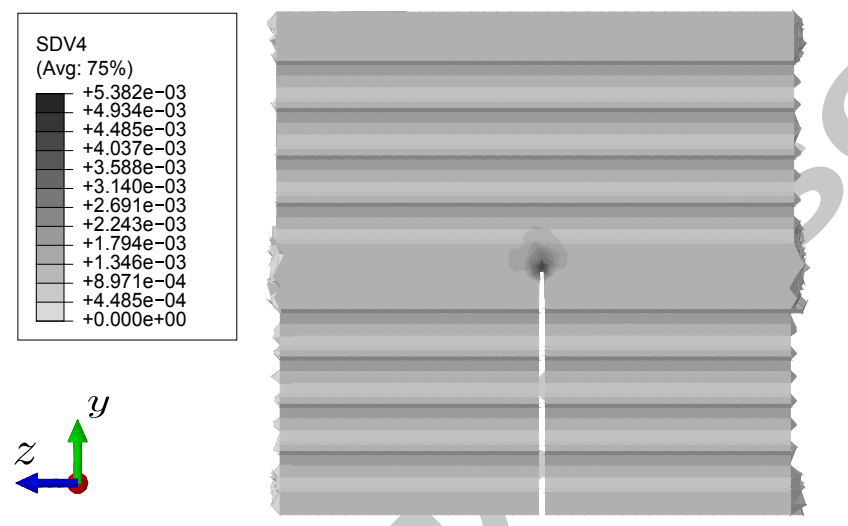

(a) Equivalent plastic strain, $\varepsilon_{e}^{p}$
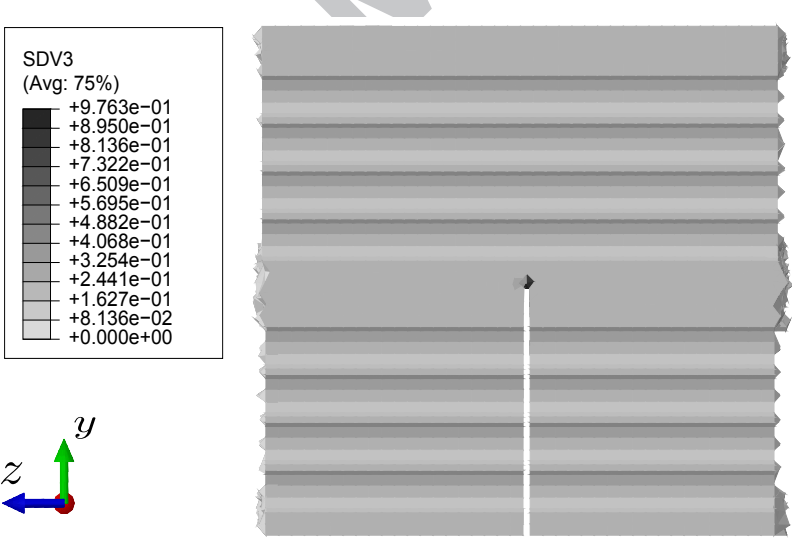

(b) Damage variable, $d_{m}$

Figure 10: Matrix contour plots at onset of crack propagation 


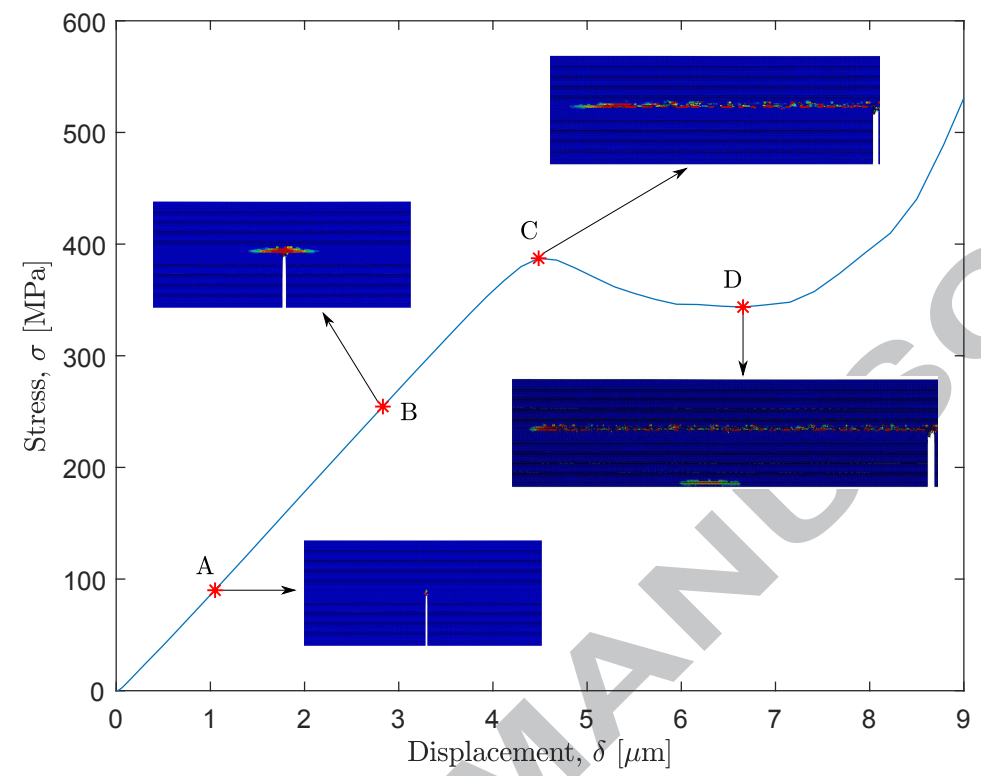

Figure 11: Numerical prediction of the stress-displacement curve of the model with $H=30 r=0.105 \mathrm{~mm}$ and $2 L=$ $10 H=1.05 \mathrm{~mm}$

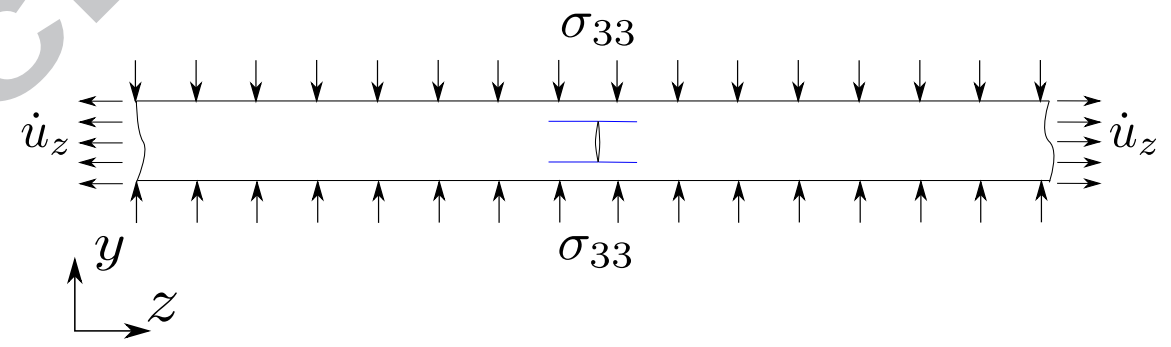

Figure 12: Loading scheme of the micromechanical model 


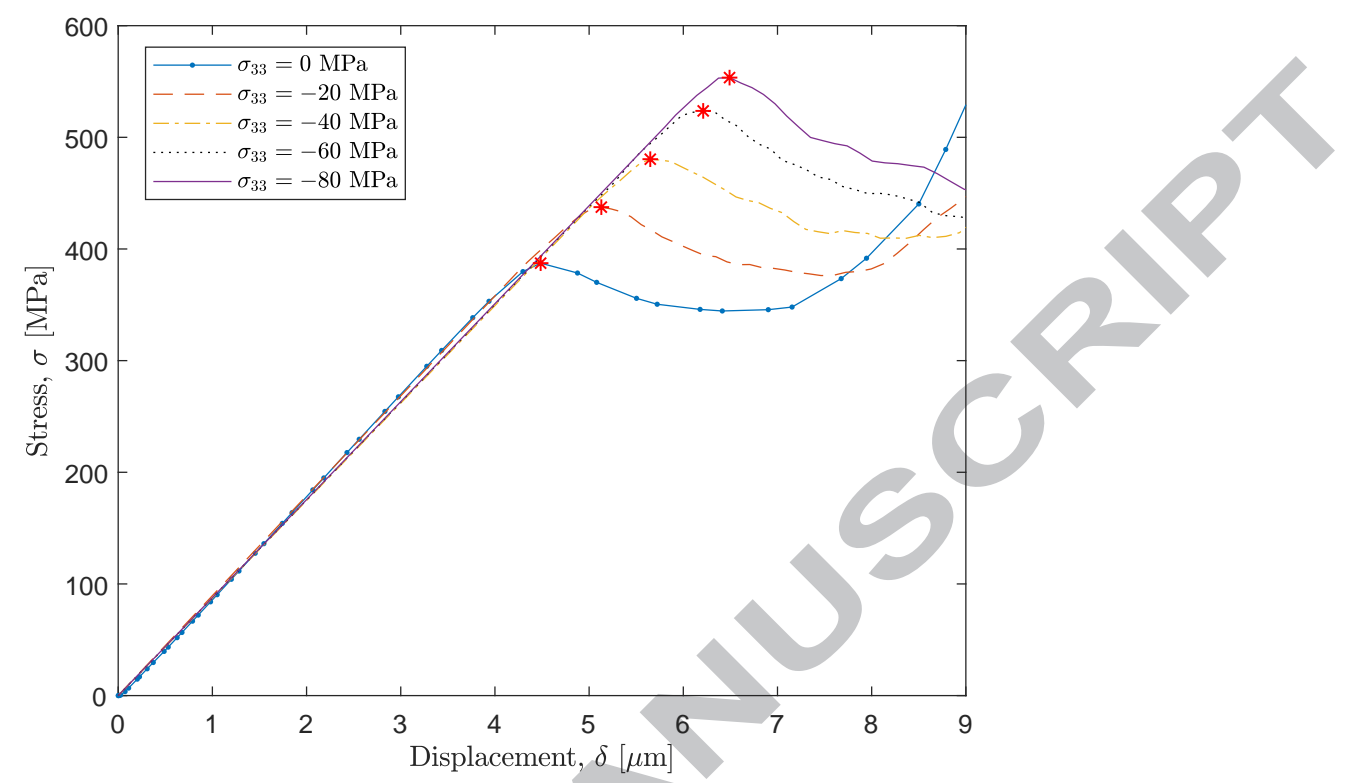

Figure 13: Numerical predictions of the stress vs. displacement curves obtained for different applied through-thickness stresses. The highlighted points indicate the loads at which the fracture process zone is completely developed

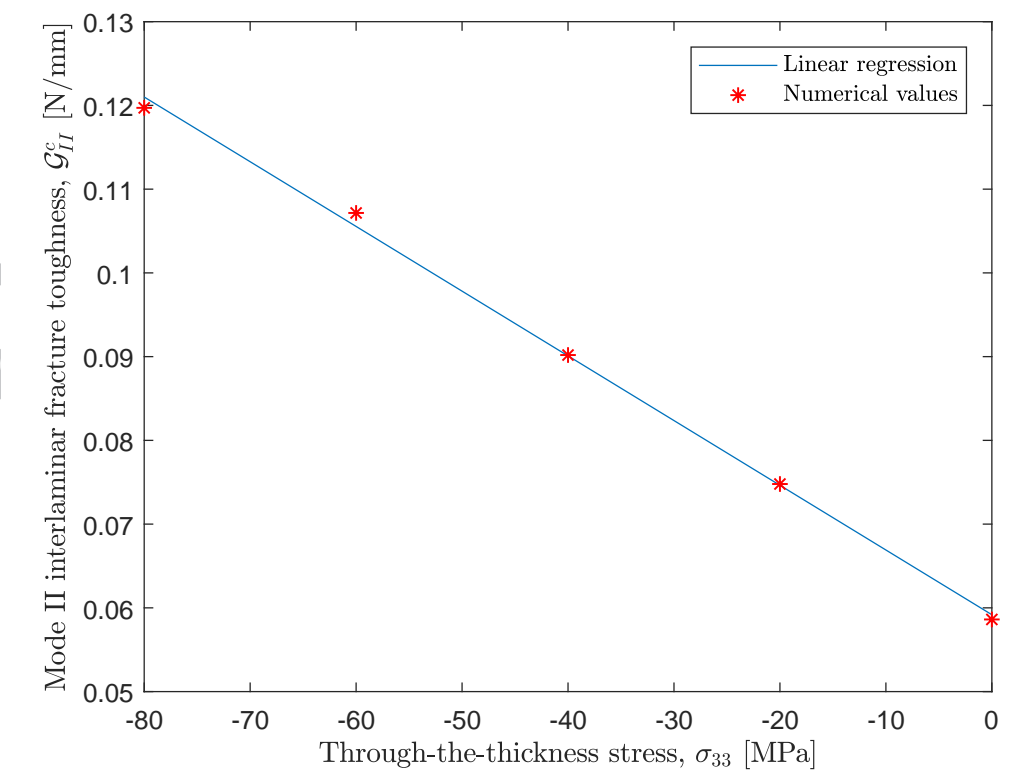

Figure 14: Mode II interlaminar fracture toughness vs. through-thickness stress 
Table 1: Fibre material properties

Material property Value

Fibre diameter

$2 r[\mathrm{~mm}]$

0.007

Fibre volume fraction

$\omega_{f}$

$60 \%$

Young's moduli

$E_{1 f}[\mathrm{MPa}]$

$E_{2 f}[\mathrm{MPa}]$

15000

Poisson's ratio

$\nu_{12 f}$

0.2

Shear moduli

$G_{12 f}[\mathrm{MPa}]$

15000

$G_{23 f}[\mathrm{MPa}]$

7000

Density

$\rho_{f}\left[\right.$ tonne $\left./ \mathrm{mm}^{3}\right]$ $1.78 \times 10^{-9}$ 
Table 2: Matrix material properties

\begin{tabular}{ll}
\hline Material property & Value \\
\hline Young's modulus & 3760 \\
$E_{m}[\mathrm{MPa}]$ & \\
Poisson's ratio & 0.39 \\
$\nu_{m}$ & \\
Coefficient of thermal expansion & $58 \times 10^{-6}$ \\
$\alpha\left[{ }^{\circ} C^{-1}\right]$ & \\
Plastic Poisson's ratio & 0.3 \\
$\nu_{p}$ & \\
Tension failure stress & 94.9 \\
$X^{t}[\mathrm{MPa}]$ & \\
Compression failure stress & 220 \\
$X^{c}[\mathrm{MPa}]$ & \\
Fracture toughness & 0.09 \\
$\mathcal{G}_{m}^{c}[\mathrm{~N} / \mathrm{mm}]$ & \\
Density & \\
$\rho_{m}\left[\right.$ tonne/mm $\left.{ }^{3}\right]$ & \\
\hline
\end{tabular}

Table 3: Fibre-matrix interface properties

Material property

Value

Interface stiffness

$K_{i}\left[\mathrm{~N} / \mathrm{mm}^{3}\right]$

$10^{8}$

Interface maximum strengths

$\tau_{1}^{0}[\mathrm{MPa}]$

$\tau_{2}^{0}[\mathrm{MPa}]$

75

$\tau_{3}^{0}[\mathrm{MPa}]$

Interface critical energy release rates

$\mathcal{G}_{I i}^{c}[\mathrm{~N} / \mathrm{mm}]$

0.002

$\mathcal{G}_{I I i}^{c}[\mathrm{~N} / \mathrm{mm}]$

0.006

$\mathcal{G}_{\text {IIIi }}^{c}[\mathrm{~N} / \mathrm{mm}]$

0.006

Mixed-mode interaction parameter (BK law [17])

$\eta$ 
Table 4: Specimen length vs. numerical prediction of the peak stress

\begin{tabular}{lc}
\hline $2 L[\mathrm{~mm}]$ & Peak stress $[\mathrm{MPa}]$ \\
\hline $4 H=0.42$ & 528.96 \\
$7 H=0.735$ & 457.83 \\
$10 H=1.05$ & 387.30 \\
$12.5 H=1.3125$ & 385.69 \\
$15 H=1.575$ & 384.77 \\
$20 H=2.1$ & 384.01 \\
\hline
\end{tabular}

Table 5: Numerical predictions of the peak stress and calculation of mode II interlaminar fracture toughness for different applied through-thickness stresses

\begin{tabular}{ccc}
\hline Applied stress $[\mathrm{MPa}]$ & Peak stress $[\mathrm{MPa}]$ & Mode II fracture toughness $[\mathrm{N} / \mathrm{mm}]$ \\
\hline 0 & 387.30 & 0.0586 \\
-20 & 437.48 & 0.0748 \\
-40 & 480.42 & 0.0902 \\
-60 & 523.66 & 0.1072 \\
-80 & 553.48 & 0.1197 \\
\hline
\end{tabular}




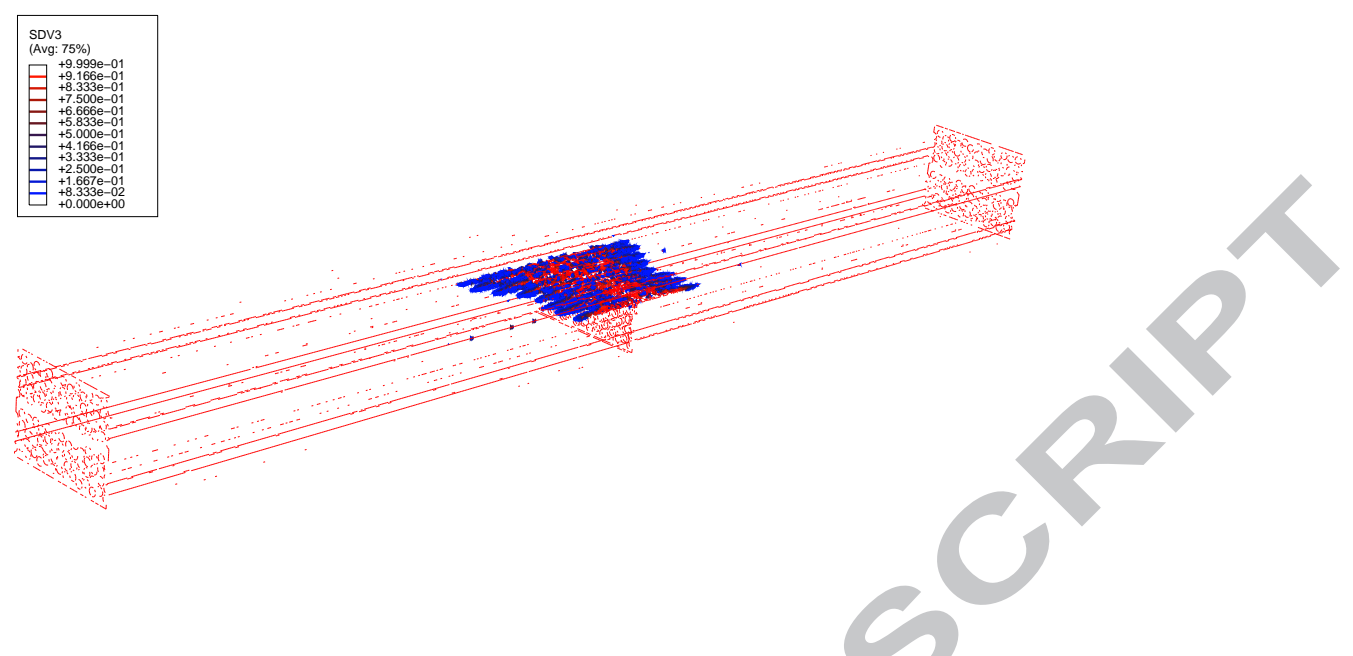

Video 1: Crack onset and propagation obtained numerically (refer to the Supplementary material A uploaded) 